\title{
Does proximity to tourist site affect the rental value of residential properties? Empirical evidence from Nigeria
}

\author{
Olalekan Oshodi ${ }^{*}$, Oyewale Oyedeji ${ }^{1}$, and Clinton A igbovboa ${ }^{1}$ \\ ${ }^{1}$ Sustainable Human Settlement and Construction Research Centre, Faculty of Engineering and the \\ B uilt Environment, U niversity of J ohannesburg, South A frica
}

\begin{abstract}
The property market plays a vital role in the economy of any nation. The industry provides jobs, investment opportunities and constructed space for productive activities, among others. Several authors have developed predictive models for the rental value of residential properties. However, little is known about the impact of tourist site on the rental value of residential properties. This study seeks to examine the effect of tourist sites on the rental value of residential properties using an artificial intelligence technique. The predictive modelling approach was utilised in this study. It was found that proximity to tourist site and security are the most important factors influencing rental prices of residential properties. In addition, the developed Neural Network (NN) model could adequately predict the rental value of residential properties $(93.75 \%$ were correctly predicted). The results of this study demonstrate that the $\mathrm{NN}$ model is a useful tool for forecasting of the rental value of properties. The findings of this study provide valuable information for policy makers, professionals in the built environment and property investors.
\end{abstract}

Keywords: Forecasting, modelling, neural network, rental value, residential property.

\section{Introduction}

Research in the real estate sector has evolved over the years. This situation has led to the development of several models for forecasting of rental values of residential properties. The process of assembling residential properties contributes to economic growth through employment generation, production in the manufacturing sector and business opportunities, among others $[1,2]$. Also, foreclosures in the real estate market have been linked to the Global Financial Meltdown [3]. These shreds of evidence found in the literature show that the residential property market is an important segment of any economy. In the existing literature, the predictive models for this class of properties focused on countries such

* Corresponding author: os.oshodi@gmail.com 
as Australia [4]; Dubai [5]; Hong Kong [6]; New Zealand [7]; Nigeria [8]; United Kingdom [9] and United States of America [10], among others.

The approach used for modelling and forecasting of the value of residential properties can be classified into two. First, modelling the relationship between economic variables and the value of residential properties [11]. Second, forecasts of the value of residential properties are generated based on attributes, such as the number of rooms [4, 7]. Despite the rapid development of residential market research, certain markets in developing countries (such as Nigeria) are under-researched. This has been attributed mainly to the lack of data [12]. Also, little is known about the impact of tourist sites on the rental value of residential properties.

The purpose of this study is to develop a predictive model for rental values of residential properties using the neural network. The goal of this study was achieved through two objectives: (i) model the relationship between the rental value of a residential property and its attributes and (ii) examine the impact of property attributes on rental value. The findings of this study provide an answer to the question 'does the tourist site affect the rental value of residential properties?". This is the main contribution of this study to the existing knowledge.

\section{Literature Review}

\subsection{Property attributes}

Research into residential property value forecasting has a long history. Some of the studies found in the literature include Abidoye and Chan [8] and Lam et al. [6], among others. Bond and Hopkins [7] found that proximity to high voltage overhead transmission lines does not affect the value of residential properties in New Zealand. Lam et al. [6] reported that the presence of a garden has a significant impact on the value of residential properties in Hong Kong. Other attributes affecting the value of residential properties include property location; a number of bedrooms; a number of toilets; a number of bathrooms; property type; a number of boy's quarters; number of parking space; age of property, number of floors and availability of sectors $[6,8,10]$. Information gleaned from the literature shows that a multiplicity of factors affect the value of residential properties.

\subsection{Forecasting techniques used in previous research}

A significant and growing body of studies has used modelling techniques for forecasting of the value of residential properties. In forecast oriented research, the process of model development can be divided into five distinct but iterative stages. First, relevant theories useful for prediction of the outcome variable are identified from the literature. Second, the theoretical constructs are operationalised into measurable constructs. Third, relevant data relating to the constructs are collected from reliable sources. Fourth, the collected data is divided into two groups (training data which is used for estimating the model and test data used for evaluating the predictive accuracy of the developed model). Finally, the model is calibrated, and the predictive performance of the model is calculated. The outcome of forecasting oriented research is useful in testing existing theories [13]. The theory upon which the model is developed is revised or discarded if the predictive accuracy of the developed model is low.

Based on a review of the literature, the techniques used for modelling and forecasting of the value of residential properties include analytical, regression (also referred to as hedonic), neural network and support vector machine, among others $[4,6,8]$. These techniques can 
be classified into two broad groups: linear and non-linear approaches. Comparative analysis of the predictive accuracy of different techniques has been used to evaluate the performance of the developed models. For example, Abidoye and Chan [14] found that the neural network model outperformed the regression model when applied to residential property value forecasting. Also, Nghiep and Al [10] reported that the predictive performance of the neural network model was better than that of the regression model when used for residential property value forecasting. Based on the findings of previous research, the neural network was used for forecasting of the rental value of residential property in this study.

\section{Study Area}

Recently, the Nigerian economy has been in a recession. This situation is primarily due to low revenue from crude oil sales. Previous research has shown that changes in crude oil prices have an impact on construction cost [15]. However, it must be noted that the effect of changes in crude oil prices on rental value is unknown. This could be attributed to the lack of quantitative data in developing countries, such as Nigeria [16]. Based on the foregoing, there have been government reforms aimed at improving the volume of internally generated revenue. Also, rent is one of the potential sources of revenue for private sector investors.

Nigeria is made up of 36 states and a federal capital territory - Abuja. According to Olaleye [17], the Nigerian property market can be classified into two groups: primary (characterised with high rental and capital values) and secondary markets (characterised with the low rental and capital values). Osun state is situated in the South-West region of Nigeria. A lot of tourist sites, which holds historical information about the Yoruba race, are located within Osun State. For example, the Osun Grove is a tourist site that attracts a large volume of tourists to Osun State [18]. Although the state contains predominantly single-family residential homes, there are some multi-unit houses and a small number of commercial properties.

\section{Research Method}

\subsection{Data}

Advancements in the field of artificial intelligence (AI) has been tremendous. This has led to the development of several techniques for modelling and forecasting. These techniques have been applied to problems in the different field of research, such as food processing [19], construction economics [20], structural mechanics [21] and structural health monitoring [22], among others. Hence, the NN, which is an AI modelling technique, was applied to rental value prediction in this research.

To achieve the first objective of this study, there is a need to collect data relating to the rental value of residential properties. To this end, transaction data were collected from real estate firms and property owners. This is because there is no centralised database for property transactions in Nigeria [8]. The collected data contained information about transaction details of properties located in Oshogbo, Osun State. The information relating to structural attributes for each property was collected. This is consistent with the approach used in previous studies $[7,8,10]$. In addition, spatial information relating to the proximity of each property to tourist site (i.e. Osun grove) was collected.

Information relating to 160 property rental transactions were retrieved, and this represents the data used for the study. The transaction data contains information on ten independent variables and one dependent variable (i.e. the rental value of the residential property). The variables in the final NN model are presented in Table 1. 
Table 1. Variables used in the model.

\begin{tabular}{|c|c|c|}
\hline Variable Name & Variable & Definition of variable \\
\hline DFCS & Distance from cultural site & $\begin{array}{l}\text { Classified into four groups }(0-200 \mathrm{~m} \text {, } \\
201-400 \mathrm{~m}, 401-600 \mathrm{~m}, 601-800 \mathrm{~m})\end{array}$ \\
\hline State & A ge of building & Numeric values of $1,2,3,4, \ldots$ \\
\hline Security & A perceived sense of security & Numeric values of $1,2,3,4, \ldots$ \\
\hline Security.S & Presence of security operatives & 1 if available and, 0 if not available \\
\hline Interior & State of building's interior & Numeric values of $1,2,3,4, \ldots$ \\
\hline Exterior & State of building's exterior & Numeric values of $1,2,3,4, \ldots$ \\
\hline Dist.to.shopping & Proximity to the shopping centre & Numeric values of $1,2,3,4, \ldots$ \\
\hline Water & Pipe-borne water & 1 if available and, 0 if not available \\
\hline Road & Road infrastructure & 1 if available and, 0 if not available \\
\hline Rooms & Number of rooms & Numeric values of $1,2,3,4, \ldots$ \\
\hline Rent & $\begin{array}{l}\text { Rental value (per annum in } \\
\text { Naira) }\end{array}$ & $\begin{array}{l}\text { Less than } 50,000 ; 50,001-100,000 ; \\
100,001-150,000 \text {; over } 150,001\end{array}$ \\
\hline
\end{tabular}

\subsection{Model Specification}

In the current study, a three-layer feed-forward neural network (NN) model was applied to the forecasting of the rental value of residential properties. NN model is inspired by the human brain. The NN model is made up of interconnected neurons whose functioning is similar to the human brain. The neurons in the $\mathrm{NN}$ model is calibrated during the learning phase. The final forecast computed by the model is largely dependent on the initial weights of the neurons. To reduce the variations in the final forecast from the $\mathrm{NN}$ model due to randomisation, an ensemble of NNs was applied in the present study. The final predictions from each NN model were averaged [23]. The architecture of the NN model is 10-H-1. The input layer has 10 neurons (i.e. 10 independent variables). The number of nodes in the hidden layer $(\mathrm{H})$ is the only parameter of the ANN model that was tuned using a grid search algorithm. The output layer (neuron) of the $\mathrm{NN}$ model is the rental value.

The predictive experiments were carried out using the R-programming [24] and minor package, which facilitates the application of artificial intelligence models (such as ANN) to real-world problems [25]. The process of developing predictive models entails two important phases: model estimation and model validation. The $\mathrm{NN}$ model was estimated by capturing the relationship between the 10 independent variables and rental value. To validate the model, the collected data were divided into two groups (i.e. training and test data set). Zhang et al. [26] mentioned that the ratio for training and test data set in previous studies include 90:10;80:20 and 70:30, respectively. For this study, the collected data were randomly divided into two groups based on $70 \%$ and $30 \%$ (112 and 48 ). 


\section{Results and Discussion}

\subsection{Results}

Artificial intelligence models are used to predict numerical values (regression) and groups (classification). In this study, the rental value of residential properties was grouped into four classes: (A) less than N 50,000; (B) N 50,001 - N 100,000; (C) N 100,001 - N 150,000; and (D) over N 150,001. For classification problems, the predictive performance of the model is based on "correctly classified" and "incorrectly classified". The predictive performance of classification models range between $0 \%$ and $100 \%$, and a value close to $100 \%$ shows perfect performance [27].

The results from model validation (i.e. prediction of the test data set using the trained $\mathrm{NN}$ model) are summarised and presented in Table 2. The overall predictive accuracy of the NN model is 93.75 percent.

Table 2. Formatting sections, subsections and subsubsections Prediction results for all for the logistic regression model

\begin{tabular}{|c|c|c|c|c|c|}
\hline \multirow{2}{*}{ Observed } & \multicolumn{4}{|c|}{ Predicted } & \multirow{2}{*}{ Accuracy (\%) } \\
\hline & A & B & $\mathrm{C}$ & D & \\
\hline A & 5 & 0 & 0 & 0 & 100.00 \\
\hline $\mathrm{B}$ & 1 & 8 & 1 & 0 & 80.00 \\
\hline $\mathrm{C}$ & 0 & 0 & 14 & 1 & 93.33 \\
\hline \multirow[t]{2}{*}{$D$} & 0 & 0 & 0 & 18 & 100.00 \\
\hline & & & & Overall & 93.75 \\
\hline
\end{tabular}

\subsection{Sensitivity Analysis}

Compared to regression, the NN model does not provide outputs which contain coefficients for each variable. This outcome makes it difficult to interpret the importance of each independent variable included in the final NN model. Hence, little is known about the contribution of each independent variable to the prediction of the outcome variable (i.e. rental value). This is the main reason AI models are called black-box models [28]. Sensitivity analysis was proposed in Cortez and Embrechts [29] as an approach for visualising the relative importance of variables included in AI models, such as NN. Figure 1 shows the relative importance of the independent variables used in the development of the NN model.

The RI value ranges between .0 and .25 , where a .0 value indicates that the attribute does not affect the rental value, while .25 connotes a highly significant contribution to the rental value of residential properties. As can be seen from Figure 1, DFCS, Security.S, Rooms and Security are the independent variables which have a significant impact on the rental value of residential properties. Surprisingly, water has the least effect on rental value. 


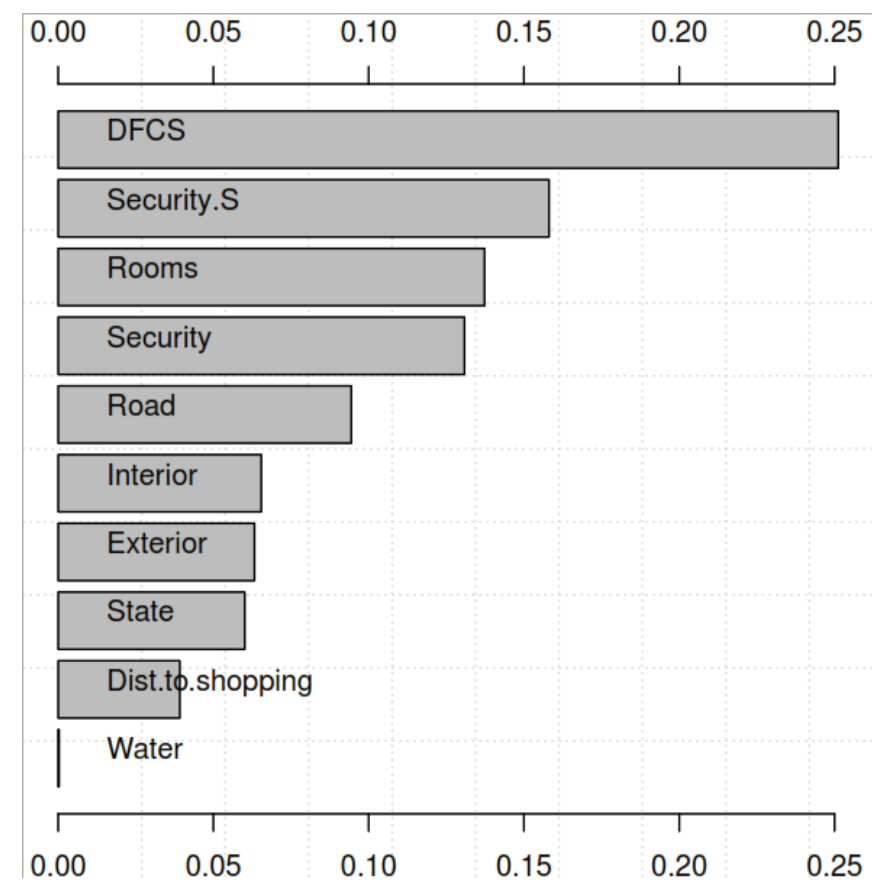

Fig. 1. The relative importance of independent variables

\subsection{Discussion of Findings}

Very little was found in the literature on the effect of tourist site on the rental value of residential properties. The present study was designed to address this gap in the literature by modelling and forecasting of the rental value of residential properties. The most exciting finding was that proximity to tourist site has a significant impact on the rental value of residential properties located within the study area. The predictive accuracy of the developed NN model is 93.75 percent. The finding of the present study also demonstrates the efficacy of using NN model for forecasting of the rental value of residential properties. Distance from the cultural site, the presence of security operatives, number of rooms and perceived sense of security around the location of the building are good predictors of the rental value of residential properties. Contrary to expectations, it was revealed that availability of pipe-borne water has no impact on the rental value of residential properties.

The results of this study will now be compared to the findings of previous work. These findings confirm that attributes of a residential property (see Table 1) are useful for predicting its value. For example, Abidoye and Chan [8] found that property attributes are good predictors of property value. Similar findings were also reported in Lam et al. [30]; McGreal et al. [9]; and $\mathrm{Li}$ and $\mathrm{Li}$ [4], among others. The findings observed in this study mirror those reported in previous studies focused on evaluating the efficacy of using AI models for forecasting of property value. The outcome shows that the relationship between the attributes of a residential property and its value is non-linear. The predictive performance of the NN model could be attributed to its ability to capture the non-linear relationship between property value and its attributes.

On the overall, the $\mathrm{NN}$ model provides a reliable forecast of the rental value of residential properties. This study has shown that proximity to a tourist site and the presence of security operatives are the two most important attributes affecting the rental value of residential 
properties. This study contributes to the existing knowledge in the field of property economics in two ways. First, it has provided evidence showing the influence of tourist sites on the rental value of residential properties. Second, this, to our (i.e. authors) knowledge, is the first study to apply classification models to the prediction of the rental value of residential properties in the context of developing countries, such as Nigeria. While the findings of the present study are promising, it must be acknowledged that not all predictors of rental value are captured in the developed model. The developed NN model can be used as a decision support tool for the prediction of the rental value of residential properties.

\section{Conclusion}

The study, reported in this paper, set out to develop a model for predicting the rental value of residential properties. Also, the outcome provides an answer to the question "does proximity to tourist site have an impact on the rental value of a residential property?" Three main findings emanate from the outcomes of this research. First, the attributes of a residential property are good predictors of its value. Second, the distance between a residential property and a tourist site has an impact on its rental value. Finally, the neural network model is excellent for forecasting of the rental value of residential properties.

The outcome of this investigation clearly shows that proximity to tourist site has an impact on the rental value of residential properties. Also, it is evident that the attributes of a residential property emerged as reliable predictors of its rental value. In general, the evidence from this study suggests that location is the most important variable that influences the rental value of a residential property. The present study contributes to the existing knowledge in the field of property economics by providing insights into the impact of tourist sites on the value of residential properties.

The findings presented in this paper are subject to certain limitations. First, the data set available for modelling is small. The lack of quantitative data remains a challenge faced by researchers in the field of construction economics and property economics. Second, the findings are based on the modelling approach. Third, the data collected is limited to a particular section of Nigeria. Despite these limitations, the use of the hold-out sample (i.e. training and test data set) ensure that the developed $\mathrm{NN}$ model is robust and reliable. This is similar to the approach used in previous studies (such as Abidoye and Chan [8]; Lam et al., [6]). The findings of the current study offer insight into the relationship between attributes of residential properties and its value. Further research is needed to establish whether proximity to a tourist site has an impact on the sale value of residential properties. Also, it would be interesting to assess the impact of tourist site on the value of commercial properties. These findings imply that the location and attributes of residential property should be taken into account when making a decision relating to the investment.

\section{Reference}

1. Y.H. Chiang, L. T ao, F.K.W. W ong, Causal relationship between construction activities, employment and GDP: The case of Hong K ong, Habitat International 46:1-12 (2015)

2. R.E. Saks, Job creation and housing construction: Constraints on metropolitan area employment growth, Journal of Urban Economics 64(1):178-195 (2008)

3. H. Jiang, X.H. Jin, C. Liu, The effects of the late $2000 \mathrm{~s}$ global financial crisis on Australia's construction demand, Construction Economics and Building 13(3):65-79 (2013)

4. H. Li, V. Li, Forecasting house rental levels: A nalytical rent model versus neural network, Journal of Urban Planning and Development 122(4):118-127 (1996) 
5. A. Hepşen, M. Vatansever, Forecasting future trends in Dubai housing market by using Box-Jenkins autoregressive integrated moving average, International Journal of Housing Markets and Analysis 4(3):210-223 (2011)

6. K.C. Lam, C.Y. Y u, C.K. Lam, Support vector machine and entropy based decision support system for property valuation, Journal of Property Research 26(3):213-233 (2009)

7. S. Bond, J. Hopkins, The Impact of T ransmission Lines on Residential Property V alues: Results of a Case Study in a Suburb of W ellington, NZ. Pacific Rim Property Research Journal, 6(2):52-60 (2000)

8. R.B. A bidoye, A.P.C. Chan, M odeling property values in Nigeria using artificial neural network, Journal of Property Research 34(1):1-18 (2017)

9. S. M cGreal, A. A dair, D. M CBurney, D. Patterson, Neural networks: the prediction of residential values, Journal of Property Valuation and Investment 16(1):57-70 (1998)

10. N. Nghiep, C. Al, Predicting housing value: A comparison of multiple regression analysis and artificial neural networks, Journal of Real Estate Research 22(3):313-336 (2001)

11. H. Mallick, M.K. M ahalik, Factors determining regional housing prices: evidence from major cities in India, Journal of Property Research 32(2):123-146 (2015)

12. R.B. A bidoye, A.P.C. Chan, A survey of property valuation approaches in Nigeria, Property Management 34(5):364-380 (2016)

13. G. Shmueli, O.R. Koppius, Predictive analytics in information systems research, MIS Quarterly 35(3):553-572 (2011)

14. R.B. Abidoye, A.P.C. Chan, Improving property valuation accuracy: a comparison of hedonic pricing model and artificial neural network, Pacific Rim Property Research Journal 24(1):71-83 (2018)

15. Olatunji, The impact of oil price regimes on construction cost in Nigeria, Construction Management and Economics 28(7):747-759 (2010)

16. K \&umu, Construction statistics review for Kenya, Construction Management and Economics 25(3):315-326 (2007)

17. Olaleye, Property market nature and the choice of property portfolio diversification strategies: The Nigeria experience, International Journal of Strategic Property Management 12:35-51 (2008)

18. K.M. W oosnam, K.D. A leshinloye, N. M aruyama, Solidarity at the Osun Osogbo Sacred Grove: A UNESCO world heritage site, Tourism Planning and Development 13(3):274291 (2016)

19. P. Cortez, A. Cerdeira, F. Almeida, T. Matos, J. Reis, Modeling wine preferences by data mining from physicochemical properties, Decision Support Systems, 47(4):547553 (2009)

20. Oshodi, O.A. Ejohwomu, I.O. Famakin, P. Cortez, Comparing univariate techniques for tender price index forecasting: Box-J enkins and neural network model, Construction Economics and Building 17(3):109-123 (2017)

21. J. Tinoco, A. Gomes Correia, P. Cortez, J et grouting column diameter prediction based on a data-driven approach, European Journal of Environmental and Civil Engineering 1-21 (2016)

22. M.S. El-A bbasy, A. Senouci, T. Zayed, F. M irahadi, L. Parvizsedghy, A rtificial neural network models for predicting condition of offshore oil and gas pipelines, Automation in Construction 45:50-65 (2014)

23. T. Hastie, R. Tibshirani, J. Friedman, The Elements of Statistical Learning: Data Mining, Inference, and Prediction (2nd ed.), N ew Y ork: Springer-Verlag (2008)

24. R Core Team., $R$ : A language and environment for statistical computing. Vienna, A ustria: R Foundation for Statistical Computing (2015) 
25. P. Cortez, Data mining with neural networks and support vector machines using the R/rminer tool. In: P. Perner, ed. Proceedings of the 10th Industrial Conference on Data Mining - Advances in Data Mining: Applications and Theoretical Aspects, July 2010, Berlin, Germany. B erlin: Springer 572-583 (2010)

26. G. Zhang, B.E. Patuwo, M .Y. Hu, Forecasting with artificial neural networks: The state of the art, International Journal of Forecasting 14:35-62 (1998)

27. P. Cortez, A tutorial on the rminer $R$ package for data mining tasks. Teaching Report, Department of Information Systems, ALGORITMI Research Centre, Engineering School, University of M inho, Guimaraes, Portugal (2015)

28. S. Dreiseitl, L. Ohno-Machado, Logistic regression and artificial neural network classification models: a methodology review, Journal of Biomedical Informatics, 35(5-6):352-359 (2002)

29. P. Cortez, M.J. Embrechts, Using sensitivity analysis and visualization techniques to open black box data mining models, Information Sciences 225:1-17 (2013)

30. K.C. Lam, C.Y. Y u, K.Y. Lam, An artificial neural network and entropy model for residential property price forecasting in Hong K ong, Journal of Property Research 25(4):321-342 (2008) 